\title{
A cincuenta años de Medellín: balance y futuro de la teología feminista latinoamericana"
}

\author{
Olga Consuelo Vélez Caro**
}

Recepción: 25 de agosto de 2018 • Aprobación: 21 de septiembre de 2018

\section{Resumen}

A propósito de la celebración de los cincuenta años de la Conferencia de Medellín nos preguntamos por la situación de la mujer y el camino que se ha hecho en la reflexión teológica para contribuir a la defensa de su dignidad y el logro de su plena participación en la sociedad y en la Iglesia. Se señalan las metas alcanzadas y los caminos pendientes.

Palabras clave: mujer, dignidad, teología feminista, liberación.

* Artículo de reflexión preparado para el Primer Congreso Internacional de Teología Latinoamericana y del Caribe: 50 años de Medellín: Iglesia y signos de los tiempos, desarrollado en la Universidad Santo Tomás entre el 16 y el 19 de octubre de 2018. Citar como: Vélez Caro, O. C. (2019). A cincuenta años de Medellín: balance y futuro de la teología feminista latinoamericana. Albertus Magnus, X(1), 89-102. Doi: https://doi.org/10.153322/5005413.5113.

** Pontificia Universidad Javeriana, Bogotá , Colombia. Orcid: http://orcid.org/0000-00024663-8005. Correo electrónico: ocvelez@javeriana.edu.co 


\title{
50 years of Medellin: Balance and future of latin american feminist theology
}

\begin{abstract}
With regard to the celebration of the 50th anniversary of the Medellín Conference, we ask about the situation of women and the path that has been taken in theological reflection to contribute to the defense of her dignity and the achievement of her full participation in the society and in the church. The achievements and the pending roads are indicated.
\end{abstract}

Keywords: woman, dignitate, feminist theology, liberation.

\section{0 anos de Medellin: equilíbrio e futuro da teologia feminista latino-americana}

\section{Resumo}

No que diz respeito à celebração do $50^{\circ}$ aniversário da Conferência de Medellín, nos perguntamos sobre a situação das mulheres e o caminho percorrido na reflexão teológica para contribuir para a defesa de sua dignidade e o alcance de sua plena participação na sociedade e na igreja. As conquistas e as estradas pendentes são indicadas.

Palavras-chave: mulher, dignidade, teologia feminista, liberação.

\section{Introducción}

Con la II Conferencia General del Episcopado Latinoamericano, la Iglesia latinoamericana empezó a adoptar un lenguaje y una perspectiva liberadora. Fue un momento de cambio y esperanza, como se señala en la presentación del Documento de Medellín: "Comienza para la Iglesia de América Latina 'un nuevo periodo de su vida eclesiástica' [...] Es la hora de la esperanza" (Consejo Episcopal Latinoamericano [Celam], 1968). Esa esperanza se vio concretada en muchos aspectos a lo largo de estos cincuenta años (también con retrocesos y persecuciones), pero que hoy podemos entenderlos mejor con la perspectiva que nos da este cincuentenario. 
En este artículo, me centraré en la realidad de la mujer porque es innegable el cambio que se ha producido en las últimas décadas y los que todavía esperamos se den en el futuro. No pretendo extrapolar el Documento de Medellín haciéndole decir lo que allí no se dijo, sino intentar rescatar los elementos liberadores que allí se expresaron y que de alguna manera dinamizaron y pueden seguir acompañando hoy el camino vivido por las mujeres en la sociedad, en la Iglesia y en el quehacer teológico. Primero, me centraré en recoger algunos aspectos del Documento de Medellín sobre la mujer; segundo, hablaré del desarrollo de la teología feminista latinoamericana; $y$, finalmente, señalaré algunos desafíos pendientes.

\section{Medellín y la realidad de la mujer}

Uno de los núcleos que caracteriza el Documento de Medellín es el de la justicia social y los pobres. Este núcleo ilumina la realidad de la mujer en dos sentidos: reconociendo su dignidad fundamental como exigencia de justicia y la mujer como pobre que, como bien expresó después el Documento de Puebla: “En esta categoría se encuentran principalmente nuestros indígenas, campesinos, obreros, marginados de la ciudad y, muy en especial, la mujer de estos sectores sociales, por su condición doblemente oprimida y marginada" (Celam, n. 1135, nota 297).

El contexto de la celebración de Medellín se corresponde con el surgimiento y avance de los movimientos feministas en varias partes del mundo, que reclaman la igualdad de derechos para las mujeres. Aunque la Iglesia no estaba en sintonía con esos reclamos, esas luchas permearon todas las instancias y es así que encontramos en Medellín afirmaciones en ese mismo sentido, que de hecho ya estaban consignadas en el Vaticano II: " "La mujer [reclama] su igualdad de derecho y de hecho con el hombre" (Celam, 1968, n. 1). Otra afirmación interesante que encontramos en el Mensaje a los Pueblos y que podemos retomar es la siguiente: “Contamos con elementos y criterios profundamente humanos y esencialmente cristianos: un sentido innato de la dignidad de todos [...] un reconocimiento de la mujer en su función irremplazable en la sociedad" (n. 0). Seguramente el contenido de esa función irremplazable en la sociedad estaba más cercano a su papel

1 El Concilio Vaticano II rechaza la discriminación en razón del sexo (Pablo VI, 1965b, n. 29), afirma la igual dignidad del varón y la mujer (n. 49), estimula la participación de la mujer en la vida cultural (n. 60) y señala la importancia de la participación de las mujeres en el apostolado de la Iglesia (Pablo VI, 1965a, n. 9). 
como esposa y madre que a lo que pedían las consignas feministas. Sin embargo, nombrarlo es importante.

En cuanto la familia, se reconoce "el patriarcado" al referirse a los cambios que está sufriendo: "El paso de una sociedad rural a una sociedad urbana, que conduce a la familia de tipo patriarcal hacia un nuevo tipo de familia, de mayor intimidad, con mejor distribución de responsabilidades y mayor dependencia de otras micro sociedades" (Celam, 1968, 1.2.a). ${ }^{2}$

Al referirse al cometido de la familia como formadora, afirma:

En efecto, la presencia e influencia de los modelos distintos y complementarios del padre y de la madre [masculino y femenino], el vínculo del afecto mutuo, el clima de confianza, intimidad, respecto y libertad, el cuadro de la vida social con una jerarquía natural pero matizada por aquel clima, todo converge para que la familia se vuelva capaz de plasmar personalidades fuertes y equilibradas para la sociedad. (Celam, 1968, n. 5)

Esta cita, a la luz de las posteriores reflexiones de la teología feminista, permitirá mostrar cómo la justificada "jerarquía natural" entre varón y mujer es precisamente lo que una reflexión feminista buscará transformar. Se señala también que "una falsa noción de masculinidad" es una de las causas de que haya abandono de la familia por parte del padre (Celam, 1968, I.3.c). Y con respecto al lenguaje que también forma parte de esta reflexión feminista, solo en tres ocasiones Medellín usa el lenguaje inclusivo (nn. 9, 17-18).

Aunque solo hallemos estas referencias, podemos entroncarnos con Medellín para nuestra reflexión ulterior, porque los núcleos liberadores que allí se expresan son fuente y horizonte del tema que nos ocupa. Medellín opera un cambio de lugar hermenéutico en la reflexión eclesial al centrarse en los pobres, opción que se convirtió en poco tiempo en la opción de toda la Iglesia latinoamericana que señala la lucha por la justicia como forma de concretar la salvación (la justicia excede lo socioeconómico y se refiere a todos los aspectos de la vida), es decir, una liberación integral. De ahí que de estos núcleos liberadores se pueda inferir que la realidad de la mujer está allí considerada porque ella es pobre y necesita esa liberación integral en todos los ámbitos de su vida tanto en lo público como en lo privado.

2 También se refiere a la catequesis de tipo "patriarcal" (Celam, 1968, n. 8). 
En otras palabras, si Medellín significó una recepción creativa del Concilio Vaticano II a partir de la situación de América Latina, las mujeres igualmente pueden hacer (y de hecho ¡la hicieron!) una recepción creativa y una relectura renovadora de Medellín a partir de sus experiencias de fe, de sus luchas emancipadoras y desde su propia conciencia y condición de mujeres (cf. Vélez, 2002, pp. 531-546). Además, Medellín fue la cuna de la teología de la liberación, en cuyo marco las mujeres latinoamericanas comenzaron a participar como sujetos del quehacer teológico. A partir de ahí se dieron los desdoblamientos de esta teología en las llamadas teologías contextuales, entre ellas, la teología feminista latinoamericana.

\section{Teología feminista latinoamericana}

La urgencia de la realidad sociopolítica y económica que marcó la teología de la liberación mantuvo "invisibilizada" la realidad de la mujer hasta una década posterior. "La experiencia de Dios en el pobre y el oprimido" (Boff, y Boff, 1986, p. 11), punto de partida de la teología de la liberación, no contemplaba la cuestión de género y, más aún, se pensaba que esta cuestión podría distraer este quehacer teológico de lo fundamental: el pobre. Sin embargo, desde dos frentes distintos, por una parte, la incidencia de los movimientos feministas ${ }^{3}$ a nivel global y, por otra, la incursión de las mujeres en la reflexión de la teología de la liberación, ${ }^{4}$ se fueron abriendo caminos de inclusión de la mujer hasta llegar a formular tal teología como "teología feminista latinoamericana". ${ }^{5}$ Sobre este camino y sus desafíos pendientes nos ocuparemos a continuación.

3 En sentido amplio, por feminismo entendemos el movimiento social que lucha por todos los derechos de las mujeres. Para un estudio más detallado de la teoría crítica feminista, cf. Amorós (1998). Al inicio, la teología feminista latinoamericana rechazaba el feminismo por su postura anticlerical y religiosa.

4 "Desde su inicio, la teología feminista hecha desde las mujeres latinoamericanas adoptó como principio central la vida de los pobres y oprimidos, situándose, consecuentemente, dentro de los cánones de la teología de la liberación. La reflexión teológica de las mujeres latinoamericanas concentró sus esfuerzos en las experiencias transformadoras de los grupos socioeclesiales donde los temas sociales y personales interactúan y se complementan entre sí, como es el caso de las mujeres" (Tepedino y Aquino, 1998, p. 14).

5 Vale la pena destacar que muchas teólogas latinoamericanas se identifican con la formulación de Elisabeth Schüssler Fiorenza "teología feminista crítica de liberación" (Schüssler Fiorenza, 1993, pp. 53-72.254, citada por Aquino, 2000, p. 43). 


\subsection{Caminar teológico feminista latinoamericano}

La teología feminista latinoamericana se ha gestado en diversos encuentros realizados en el continente, convocados por diferentes agrupaciones. Un primer paso fue la toma de conciencia de las mujeres de su ser actoras/sujetos de la teología. Hasta entonces no se había incorporado la visión de las mujeres en la teología (ni siquiera en la teología de la liberación de Gustavo Gutiérrez). El punto de partida del trabajo teológico de las mujeres fue su experiencia de opresión y su experiencia de fe. Se consideró que la maternidad no era el único aspecto para valorar a la mujer, por el contrario, ella es también "mediadora del Espíritu". Se denunció el mundo patriarcal que limita a las mujeres al ámbito privado exaltando las cualidades atribuidas a la mujer, tales como sensibilidad, imaginación, intuición, mientras los varones están destinados para el ámbito público en el que aparecen como seres racionales, objetivos, forjadores del futuro.

En la década de 1980, se fueron delineando las características del quehacer teológico femenino. Es una teología que se realiza de forma comunitaria y relacional; alegre, celebrativa y marcada por el buen humor; integradora de las distintas dimensiones humanas: fuerza y ternura, alegría y llanto, intuición y razón; militante porque participa en el conjunto de los procesos liberadores; reconstructora de la historia de las mujeres tanto en los textos bíblicos como en la historia de nuestros pueblos.

Hasta entonces se hablaba de teología femenina o teología hecha por mujeres. Pero se fue entendiendo que la opresión de género revelaba que no solo lo sociopolítico oprimía a las mujeres sino también lo cultural. Así comienza a introducirse la perspectiva de género y el término feminista en la década de 1990. No fue fácil asumirlo porque se daba una mutua desconfianza entre las feministas y las teólogas. Pero, pese a las connotaciones negativas que podía tener esta palabra al estar relacionada con el feminismo del primer mundo (que tenía otras preocupaciones) y con el recelo que suscita en las Iglesias, expresaba la ruptura que se quería establecer con el orden vigente y proponía una nueva forma de ser y de vivir la realidad. Asimismo, se incorporó la categoría género porque permite develar las relaciones de poder que se han establecido entre los géneros que llevan a subordinar lo femenino a lo masculino ${ }^{6}$ e invita a construir nuevas relaciones de género para favorecer un nuevo orden mundial.

6 Schüssler Fiorenza (2000) acuñó el neologismo "kyriarcado" que significa "el gobierno del emperador/amo/señor/padre/esposo sobre sus subordinados. Con ese término se quiere indicar que no todos los hombres dominan y explotan a todas las mujeres indiferenciadamente 
La teología feminista latinoamericana ha asumido lo intercultural y lo interreligioso y la preocupación ecológica en la vertiente llamada ecofeminismo (Gebara, 1993, pp. 71-124). También la violencia contra las mujeres ha sido un tema que ha ido tomando cada vez más fuerza porque se constata que la sufren en todos los ámbitos y por diversas razones: familiar, eclesial, racial, sexual, económica, cultural e intelectual. Todas estas violencias reflejan la violencia estructural que sufren las mujeres y que no puede ser tolerada. La preocupación por la corporeidad y el uso del lenguaje femenino constituye otro de los empeños de la teología feminista. Es necesario desestigmatizar el cuerpo femenino de su relación con el pecado.

\subsection{Logros y desafíos pendientes}

\subsubsection{Hermenéutica bíblica y reflexión teológica}

El apartado anterior nos permitió trazar a grandes rasgos el desarrollo de la teología feminista. Asombra ver la evolución que se va perfilando a lo largo del tiempo y alegra constatar la conciencia más nítida y comprometida de dicho caminar. La teología feminista latinoamericana la definía María Pilar Aquino en 2000 como

una reflexión crítica sobre la vivencia que las mujeres y hombres tenemos de Dios en nuestras prácticas que buscan transformar todas las instituciones y sistemas que producen empobrecimiento y violencia contra las mujeres y hombres, con el fin de avanzar hacia nuevas relaciones sociales gobernadas por la justicia y la integridad de vida, en un ambiente cultural libre de dominación patriarcal. (p. 36)

En estos dieciocho años que han pasado, esa formulación sigue vigente, aunque adquiere más diversidad de campos, incorporación de nuevos contextos, respuestas a nuevos desafíos.

Desde esa perspectiva, hablar de teología feminista latinoamericana es hablar de "teologías" porque a lo largo del continente son distintos y amplios los énfasis y enfoques que se consolidan. En primera instancia, hay que anotar los

sino que existe una compleja pirámide social de dominaciones y subordinaciones graduadas que se ha establecido en la sociedad donde unos (varones o mujeres) explotan y subordinan a otros (varones o mujeres) desde una mentalidad patriarcal, blanca, eurocéntrica, heterosexual, etc., introyectada en la sociedad en general" (p. 32). 
desdoblamientos contextuales que de hecho se han realizado tanto en perspectiva negra como indígena. En el primer caso, el objetivo es "articular críticamente la revelación de Dios en la vida cotidiana de las mujeres negras y en la historia del pueblo negro, vista como historia de salvación-liberación" (Aquino, 2000, p. 43). Para la teología feminista negra latinoamericana, es imprescindible develar todos los elementos ideológicos que han legitimado durante siglos el racismo, el sexismo y el colonialismo. Las mujeres negras sienten la urgencia de construir su identidad y encontrar en la divinidad una palabra liberadora que reconstruya y libere la realidad del pueblo negro, discriminado y estigmatizado durante tantos siglos. Para este trabajo, la dimensión ecuménica ha sido un horizonte que ha favorecido la apertura y el diálogo con otras expresiones religiosas.

Respecto de la teología feminista indígena, hay que anotar que, si por una parte ha tenido la ventaja de conectar la realidad de la mujer con la madre tierra y la posibilidad de enriquecer la experiencia de la divinidad con la identidad de las culturas ancestrales, por otra, ha tenido más dificultad para incorporar los discursos de género en este quehacer teológico, porque la cosmovisión indígena se resiste mucho más a dejarse permear por los cambios que conlleva la categoría género. Tales culturas negadas sistemáticamente desde los tiempos de la Conquista han de transformarse desde dentro para integrar en su cosmovisión una nueva manera de ser varones y mujeres, y una forma distinta de relacionarse.

Desde este caminar teológico feminista latinoamericano, la pregunta que nos surge es sobre las realizaciones teológicas alcanzadas y los desafíos pendientes. ¿Qué frutos podemos recoger de esta tarea? ¿Cuáles son las contribuciones que pueden destacarse y que se van incorporando al quehacer teológico universal? Sin pretender nombrar todas las realizaciones, podemos señalar algunos principios fundamentales de los que parten las teologías feministas ${ }^{7}$ y algunos logros bíblicos y sistemáticos que se van alcanzando. Todo lo que podamos señalar aquí es corto frente a la riqueza de un trabajo teológico que no siempre es socializado continentalmente y, por eso, las afirmaciones aquí expresadas son pequeños acercamientos a lo que ha de completarse con la colaboración de todas las teólogas de todos los rincones del continente. Entre los principios básicos podemos señalar:

- La afirmación fundamental de la igual dignidad del varón y la mujer. Igualdad que viene dada desde el acto creador (Gn 1, 27) y reafirmada por el bautismo cristiano.

7 Como ya indicamos, hablamos de "teologías feministas" en plural porque son varias y distintas los énfasis y las perspectivas asumidos por las teólogas del continente. 
- $\quad$ El testimonio de la Escritura de la presencia de la mujer en la historia salvífica tanto en el Antiguo como en el Nuevo Testamento.

- La necesidad de integrar al quehacer teológico todas aquellas dimensiones del ser humano que se han reservado a la mujer, como la ternura, la intuición, la acogida, el servicio, la generosidad, la sensibilidad, entre otras.

- El imperativo ético de denunciar la situación de subordinación y violencia vivida por las mujeres.

- La necesidad de reconstruir la historia de las mujeres, tanto en los textos bíblicos como en la historia de nuestros pueblos, inspirándose en las mujeres que, a partir de su propia realidad, han sido símbolos de lucha y resistencia, sabiduría y liderazgo, solidaridad y fidelidad, justicia y paz.

- Apropiación de las categorías críticas feministas de género como opción epistemológica en el quehacer teológico.

- Incorporación de estudios interdisciplinares e interculturales para articular la racionalidad afectiva, la estética y la sabiduría desde el imaginario popular. Recientemente se comienzan a incorporar los estudios poscoloniales.

- Reconstrucción de los orígenes cristianos y afirmación decidida del "discipulado de iguales" 8 para orientar un modelo eclesial y una participación de la mujer más acorde con la Iglesia de los orígenes.

En este camino, es importante destacar la hermenéutica bíblica latinoamericana que es una de las tareas de la teología feminista más desarrollada. Se comenzó recuperando las mujeres en la Biblia y el papel que han desempeñado en la historia de la salvación. Posteriormente se han ido interpretado los diferentes textos bíblicos desde el ámbito de las mujeres que han recuperado las imágenes femeninas de Dios y su acción salvífica para mujeres y varones. Se lee la pasión y resurrección de Jesús desde los sufrimientos y deseos de liberación de las mujeres. También el Espíritu Santo es visto como femenino. Se quiere liberar a Dios de una concepción solo varonil y recuperar la integralidad del Dios Trino que es Madre y Padre, que es humanidad (varón y mujer).

Este trabajo bíblico se ha caracterizado por liberarse de la manera de expresar a Dios desde claves androcéntricas y patriarcales, revalorizar los rasgos asignados a las mujeres como presentes en Dios mismo y por ende en el género

8 Expresión de Schüssler Fiorenza. 
humano (varón y mujer; maternidad/paternidad, abnegación, ternura), acoger el cuerpo y lo cotidiano como categorías hermenéuticas, trabajar la fiesta, la alegría, el goce de la corporeidad y la sexualidad (Cantar de los Cantares) como parte integrante del desarrollo teológico.

Además de este trabajo hermenéutico, el trabajo sistemático está siendo cada vez más rico y está tocando todos los tratados clásicos de la teología. Temas de cristología, antropología teológica, eclesiología, misterio de Dios, pneumatología, mariología, etc., ${ }^{9}$ están siendo abordados, los cuales han aportado los resultados de estas reflexiones al patrimonio teológico universal. Sin embargo, el camino por recorrer aún es vasto y amplio. $\mathrm{Y}$, por tanto, los desafíos son inmensos porque la teología feminista latinoamericana aún necesita ganar más espacio para ser reconocida en la propia comunidad teológica, en el ámbito universitario y en la Iglesia.

\subsubsection{Desafíos pendientes}

La teología feminista latinoamericana, como todas las teologías del continente, se ve abocada a continuar su desarrollo y a responder a los desafíos o a los "signos de los tiempos" que este presente trae. No es un quehacer que conoce el punto de llegada sino que en perspectiva de camino ha de mantenerse actual y vigente, y ha de recorrer nuevos senderos.

Como expresó la teóloga Marilú Rojas Salazar en el Congreso Continental de Teología, “las realidades de exclusión, marginación, violencia, feminización de la pobreza e injusticia contra las mujeres son problemas transculturales, transreligiosos y transepistémicos" (Rojas, 2015). Es decir, atraviesan todas las culturas, todas las religiones y suponen una nueva manera de conocer que permita resituar la identidad y dignidad de las mujeres en el lugar central que les corresponde en los procesos de conocimiento y no en una posición subordinada, como se ha ubicado, tradicionalmente, en la racionalidad occidental.

En esa línea hoy, sigue siendo urgente continuar el trabajo de la teología feminista latinoamericana en varias direcciones: seguir rescatando la vida cotidiana, lo lúdico, la fiesta, de manera que responda a una visión más integral del ser humano, y afianzar una visión positiva del cuerpo, la sexualidad y el placer,

9 Entre los muchos escritos que podrían nombrarse, reseñamos aquí algunos significativos más recientes: Bingemer (2004, 2005), Corpas de Posada (1985), García, Vélez y Vivas (2004), Gebara (2002), Johnson (2003a, 2003b, 2007), Navia (2001a, 2001b), Schickendantz (2005), Schüssler Fiorenza (2000, 2003, 2011), Tamez (2003, 2010), Vivas (2004) y Vélez (2018). 
porque son aspectos que tradicionalmente han influido en la visión subordinada de la mujer y le han impedido un desarrollo pleno e integral. Una articulación más consistente entre las teologías feministas indias, negras y ecofeministas que visibilicen más el trabajo teológico e influyan en un ámbito más universal; repensar, reconstruir y dar forma nueva a la ética feminista que integra lo social y lo sexual; seguir profundizando en la reconstrucción feminista de los conceptos y temas centrales en teología sistemática, tales como Dios, Jesucristo, Iglesias, espiritualidad, sacramentos, gracia, pecado, vida, etc.; sistematizar las experiencias litúrgicas y los rituales feministas que celebran las resistencias y victorias de nuestras comunidades por una realidad libre de sexismo y de violencia sexual; y proponer un discurso antropológico teo-ético alternativo.

Es necesario deconstruir el lenguaje y las prácticas teo-éticas que producen, sostienen y legitiman la violencia contra las mujeres y construir un discurso liberador de resistencia y bienestar, y seguir empleando un lenguaje sobre Dios, que no sea exclusivamente masculino, porque ese lenguaje refleja las estructuras de opresión y de violencia patriarcales. Se debe reconstruir una imagen de Dios como modelo comunitario de participación y relacionalidad. El bien común incluye la integridad de la creación, puesto que la violencia perpetrada contra la persona humana y contra la naturaleza están interconectadas.

También en tiempos de rescate de la espiritualidad urge una espiritualidad que favorezca esa nueva mirada sobre las relaciones de género y que posibilite nuevas integraciones de todas las dimensiones humanas en las liturgias y en los rituales. La espiritualidad ha de recuperar la riqueza de las múltiples formas de expresión humana lo mismo que su carácter apofático y místico que contempla y queda inmerso en el misterio divino que es siempre "mayor". No queda ajeno a todo esto seguir buscando métodos teológicos que garanticen la profundidad y pertinencia de las teologías feministas latinoamericanas, capaz de integrar otras racionalidades y sentires, en otras palabras, una visión más holística e integral que garantice esa comunión con Dios, con los demás, consigo mismo y con toda la creación.

\section{Conclusión}

La teología feminista latinoamericana constituye una palabra profética para la humanidad porque su mensaje apunta a la construcción de una nueva sociedad donde la inclusión de las mujeres devuelva el rostro original de la creación divina donde Dios “creó al ser humano a imagen suya, a imagen de Dios le creó, varón 
y mujer los creó" (Gn 1, 27). La teología feminista comunica la buena noticia de la igualdad fundamental entre todos los seres humanos. Una afirmación que no es "teórica", "universal" o "abstracta", sino que considera a los sujetos concretos - las mujeres - en sus condiciones particulares de sexo, raza y condición social. Si en los inicios de esta teología se proclamó la necesidad de mirar la realidad humana desde la perspectiva de la mujer, hoy se exige una resignificación de su ser y misión, al igual que la del varón, y su trabajo va mucho más allá de esa etapa inicial. Toda la teología está llamada a reconstruirse y a dejarse enriquecer con las nuevas categorías de análisis que ha incorporado esta teología y que permiten una nueva visión, más integral de la revelación divina y su sistematización teológica actual.

En realidad, todo trabajo teológico es un "programa de acción". La teología feminista latinoamericana implica una postura existencial, una transformación de mentalidades y estructuras, un partir de la realidad de las mujeres, iluminarla desde la fe y volver a ella para transformarla. Su desarrollo y consolidación contribuye decisivamente en devolver el lugar negado a las mujeres por tantos siglos y favorece su mayor desarrollo integral, al mismo tiempo que incorpora a los varones en esta misma búsqueda. Compromete a los dos géneros en la construcción de un mundo que hace presente de manera más clara el Reino de Dios, no solo como una exigencia ética, sino como imperativo de la fe en el Dios creador del género humano (varón y mujer, a los que les confió el devenir de la historia). Solo una humanidad que reconozca la dignidad fundamental de todos los seres humanos puede realizar el designio salvífico de Dios de llevar todo a su plenitud, y cristificar en Él toda la realidad.

Finalmente, es importante anotar que la teología feminista latinoamericana no es tarea de las mujeres. Tiene que ser un empeño común, que sume esfuerzos y apele continuamente a la autenticidad humana y evangélica de nuestro ser teólogos y personas de fe, porque lo que está en juego no es una realidad particular, una teología contextual o un movimiento social, sino el género humano llamado a ser imagen y semejanza de Dios Trinidad.

Señalamos al inicio que en Medellín se afirmó la igualdad fundamental entre varón y mujer y la legitimidad de reclamar ese derecho. Todo el camino feminista que hemos trazado ha perseguido hacerlo posible. Mucho se ha avanzado, falta mucho más. Que el impulso liberador de Medellín y la esperanza que engendró hace cincuenta años sea hoy un nuevo impulso para no detener el paso sino para dar muchos más. Un trabajo teológico feminista que promueva la identidad y el reconocimiento pleno de las mujeres en todas las instancias es signo de ese reino anunciado por Jesús que no hace diferencia entre "judío y griego, esclavo y libre, entre varón y mujer, porque todos son uno en Cristo Jesús" (Ga 3, 20). 


\section{Referencias}

Amorós, C. (1988). El punto de vista feminista como crítica. En C. Bernabé (Ed.), Cambio de paradigma, género y eclesiología (pp. 21-36). Navarra, España: Verbo Divino.

Aquino, M. P. (2000). El siglo de las mujeres: teología latinoamericana. Christus: Revista de teología y ciencias humanas, 720, 34-45.

Bingemer, M. C. (2004). A argila e o Espírito: ensaios sobre ética, mística e poética. Río de Janeiro, Brasil: Garamond.

Bingemer, M. C. (2005). Um rosto para Deus? São Paulo, Brasil: Paulus.

Boff, L. y Boff, C. (1986). Cómo hacer teología de la liberación. Bogotá, Colombia: Paulinas.

Corpas de Posada, I. (1985). Pareja abierta a Dios: estudio teológico sobre la experiencia de pareja. Bogotá, Colombia: Pontificia Universidad Javeriana.

Consejo Episcopal Latinoamericano. (1968). Documento de Medellín. Recuperado de http://www.diocese-braga.pt/catequese/sim/biblioteca/publicacoes_online/91/ medellin.pdf

Consejo Episcopal Latinoamericano. (1979). Documento de Puebla. Recuperado de https://www.celam.org/documentos/Documento_Conclusivo_Puebla.pdf

Consejo Episcopal Latinoamericano. (2014). Las cinco conferencias generales del Episcopado Latinoamericano. Bogotá, Colombia: Autor.

García G., D., Vélez Caro, O. C. y Vivas Albán, M. del S. (2004). Reflexiones en torno al feminismo y al género. Bogotá, Colombia: Pontificia Universidad Javeriana.

Gebara, I. (1993). Construyendo nuestras teologías feministas. Tópicos, 90, 71-124.

Gebara, I. (2002). La sed de sentido: búsquedas ecofeministas en prosa poética. Montevideo, Paraguay: Doble Clic.

Johnson, E. (2003a). La cristología hoy: olas de renovación en el acceso a Jesús. Santander, España: Sal Terrae.

Johnson, E. (2003b). Truly our sister: A theology of Mary in the communion of saints. Nueva York, EE. UU.: Continuum.

Johnson, E. (2007). Quest for the living God: Mapping frontiers in the theology of God. Nueva York, EE. UU.: Continuum.

Navia Velasco, C. (2001a). La ciudad interpela a la Biblia: propuesta de teología bíblica. Quito, Ecuador: Verbo Divino.

Navia Velasco, C. (2001b). Jesús de Nazaret, miradas femeninas. Quito, Ecuador: Tierra Nueva.

Pablo VI. (1965a). Apostolicam actuositatem. Recuperado de http://www.vatican.va/ archive/hist_councils/ii_vatican_council/documents/vat-ii_decree_19651118_ apostolicam-actuositatem_sp.html 
Pablo VI. (1965b). Gaudium et spes. Recuperado de http://www.vatican.va/archive/ hist_councils/ii_vatican_council/documents/vat-ii_const_19651207_gaudium-etspes_sp.html

Rojas Salazar, M. (2015). Tendencias interculturales hacia una espiritualidad ecofeminista liberadora. Trabajo presentado en Congreso Continental de Teología, Rio Grande do Sul, Brasil.

Schickendantz, C. (Ed.) (2005). Cultura, género y homosexualidad: estudios interdisciplinarios. Córdoba, Argentina: EDUCC.

Schüssler Fiorenza, E. (1993). Discipleship of equals: A critical feminist ekklèsia-logy of liberation. Nueva York, EE. UU.: Crossroad.

Schüssler Fiorenza, E. (2000). Cristología feminista crítica. Jesús, Hijo de Miriam, profeta de Sabiduría, Madrid, España: Trotta.

Schüssler Fiorenza, E. (2003). Los caminos de la sabiduría: una introducción a la interpretación feminista de la Biblia. Santander, España: Sal Terrae.

Schüssler Fiorenza, E. (2011). Transforming vision: Explorations in feminist theology, Minneapolis, EE. UU.: Fortress Press.

Tamez, E. (2003). Las mujeres en el movimiento de Jesús, el Cristo. Quito, Ecuador: Consejo Latinoamericano de Iglesias.

Tamez, E. (2010). San Marcos frente a la guerra y la violencia: una relectura desde el contexto colombiano. Medellín, Colombia: Iglesia Colombiana Metodista.

Tepedino, A. M. y Aquino, M. P. (Eds.) (1988). Entre la indignación y la esperanza: teología feminista latinoamericana. Bogotá, Colombia: Indo-American Press.

Vélez Caro, O. C. (2002). La mujer y los pronunciamientos eclesiales. Theologica Xaveriana, 143, 531-546.

Vélez Caro, O. C. (2012). Balance y futuro de la teología feminista. Revista Alternativas, 44, 89-110.

Vélez Caro, O. C. (2018). Cristología y mujer: una reflexión necesaria para una fe incluyente. Bogotá, Colombia: Pontificia Universidad Javeriana.

Vivas Albán, M. S. (2004). Mujeres que buscan liberación: identidad de la mujer. Bogotá, Colombia: Pontificia Universidad Javeriana. 